\title{
Seasonal Incidence of Fruit Fly (Zeugodacus tau) in Cucurbit Ecosystem in Tripura
}

\author{
Navendu Nair ${ }^{1 *}$, Prasenjit Pal $^{2}$ and Dilip Nath ${ }^{3}$ \\ ${ }^{1}$ Department of Agriculture Entomology, College of Agriculture, Tripura, India \\ ${ }^{2}$ Department of Extension and Social Sciences, College of Fisheries, CAU, Tripura, India \\ ${ }^{3}$ Department of Zoology, Holy Cross College, Tripura, India \\ *Corresponding author
}

\section{A B S T R A C T}

\begin{tabular}{l} 
Ke y w o r d s \\
$\begin{array}{l}\text { Zeugodacus tau, } \\
\text { Fruit fly, Cucurbits, } \\
\text { Seasonal incidence, } \\
\text { Tripura }\end{array}$ \\
\hline Article Info \\
$\begin{array}{l}\text { Accepted: } \\
10 \text { October } 2020 \\
\text { Available Online: } \\
10 \text { November } 2020\end{array}$ \\
\hline
\end{tabular}

Fruit fly (Zeugodacus tau) is one of the most destructive pests which cause extensive damage to cucurbitaceous crops in Tripura as well as many other states of India. The present study of two years duration was carried out to investigate the seasonal incidence of adult males of $Z$. tau in relation to abiotic factors. The study was carried out in cucurbit ecosystem in Tripura from July, 2015 to June, 2017. Para- pheromone lure (cue-lure) baited traps were used for catching male fruit flies. The population of male fruit flies showed almost similar fluctuation during the study period with two peaks in end of March to April and September-October. The numbers of fruit flies captured in cue lure baited traps correlated positively with temperature, relative humidity and rainfall. Maximum temperature and minimum temperature have significant influence on Z. tau population.

\section{Introduction}

Zeugodacus tau (Walker) (Diptera: Tephritidae), a quarantine pest of international concern, has become widespread and economically important in South and Southeast Asia ( $\mathrm{Li}$ et al, 2020). This insect species attacks more than 50 economically important crop species, especially cucurbitaceous plants and other fleshy fruits (Allwood et al., 1999; Kapoor, 2005/ 6 and Singh et al., 2010). According to Drew and Romig (2013) this fruit fly species has been reported to infest fruits of nine plant families, primarily species of Cucurbitaceae.
In Tripura it coexists with Z. cucurbitae in Cucurbit ecosystem and causes enormous losses to all kind of commonly grown cucurbitaceous crops (Nair et al, 2017). Like $B$ cucurbitae, males are attracted to the para pheromone cue-lure [4 (P-acetoxyphenyl-2butanone)]. Monitoring of pest population is necessary for formulating effective management strategies against any pest. Though enough works on seasonal incidence of Z. cucurbitae have been done so far throughout India but available information regarding this aspect for $Z$. tau is comparatively very less. Moreover, seasonal incidence of any pest may vary from place to 
place due to variation in climatic conditions. Occurrence of $Z$. tau at high population densities is associated with high levels of damage and could lead to high economic losses (Boopathi, 2017), so the present work was envisaged to find out the seasonal incidence of $B$. tau in Cucurbit ecosystem in Tripura and also to know the effect of weather parameters on population dynamics of this pest species so that appropriate time of action can be determined for effective management of this pest.

\section{Materials and Methods}

The present study was carried out in 'Experimental Farm' of College of Agriculture, Lembucherra, Tripura from July, 2015 to June, 2017. Different cucurbitaceous crops such as cucumber (Cucumis sativus), bitter gourd (Momordica charantia), spiny gourd (Momordica dioica), sponge gourd (Luffa cylindrica), ridge gourd (Luffa acutangula), bottle gourd (Lagenaria siceraria), snake gourd (Trichosanthes cucumerina), pointed gourd (Trichosanthes dioica), ash gourd (Benincasa hispida), pumpkin (Cucurbita moschata) and water melon (Citrullus lanatus) as per their growing seasons were grown in the 'Experimental Farm' following recommended package of practices except for the plant protection measures to create a cucurbit ecosystem throughout the study period for attracting fruit flies.

Traps baited with para- pheromone lures (cuelure) [4 (P-acetoxyphenyl-2-butanone)] were installed at ten sites for catching male fruit flies. The traps used for monitoring fruit flies were prepared with one litre plastic mineral water bottles by following the methods modified after Raghuvanshi et al., (2012). The traps were hung about 1.5 meters above the ground and a distance of at least $300 \mathrm{~m}^{2}$ between the traps was maintained. Trapped flies from each trap were brought to the laboratory separately at every seven days intervals for taking observations and mean trap catches were calculated for every week throughout the experiment. Data was recorded at weekly intervals starting from 27th standard week of 2015 to 26th standard week of 2017.

The influence of weather factors on trap catches of fruit flies were studied by using the meteorological data collected from ICAR, Lembucherra, Tripura. Correlation and Regression study was made between weekly trap catches of fruit flies and mean weather parameters namely maximum temperature, minimum temperature, relative humidity and rainfall for every standard week.

\section{Results and Discussion}

\section{Seasonal incidence}

Almost similar pattern of population fluctuation of adult fruit flies were recorded throughout the present study period (Table 1 and Fig. 1). The adult flies remained abundant throughout the study periods in the cucurbit ecosystem except during the winter months. Though the population of adult males was low ( $\leq 20$ flies/trap/week) during the cooler months i.e. during November to January but it had never become zero. 5-18 adult male flies per trap were caught from $45^{\text {th }} \mathrm{SW}$ of 2015 to $5^{\text {th }} \mathrm{SW}$ of 2016 and 9- 20 adult male flies per trap were caught from $45^{\text {th }} \mathrm{SW}$ of 2016 to $5^{\text {th }}$ SW of 2017. Lowest trap catches were recorded on $52^{\text {nd }} \mathrm{SW}$ of $2015 \quad$ (5 flies/trap/week) and $51^{\text {st }}$ SW of 2016 (9 flies/trap/week). Moderate to high trap caches (more than 20 flies/trap/week) were recorded through out the remaining period of the present study i.e. from February to October months. Two peaks in the fly population were recorded during the present study. One population peak was during last week of 
March to April and the other one was during September - October. 49-64 flies were captured per trap per week from $35^{\text {th }}$ to $42^{\text {nd }}$ SW of 2015 (maximum on $40^{\text {th }} \mathrm{SW}$ ) and 4468 flies were captured per trap from $36^{\text {th }}$ to $43^{\text {rd }} \mathrm{SW}$ of 2016 (maximum on $42^{\text {nd }} \mathrm{SW}$ ). 63 83 flies/trap/week were trapped from $13^{\text {th }}$ to $17^{\text {th }} \mathrm{SW}$ of 2016 with the highest trap catches on $14^{\text {th }} \mathrm{SW}$ and $56-72$ flies/trap/week were trapped from $14^{\text {th }}$ to $17^{\text {th }} \mathrm{SW}$ of 2017 with the highest trap catches on $14^{\text {th }} \mathrm{SW}$. The seasonal incidence of $Z$. tau has been depicted graphically in Fig. 1.

Table.1 Seasonal incidences of fruit fly (Zeugodacus tau)

\begin{tabular}{|c|c|c|c|c|c|c|c|}
\hline $\begin{array}{l}\text { standard } \\
\text { week }\end{array}$ & $\begin{array}{c}\text { Per Week } \\
\text { catches of } \\
\mathrm{Z} \text { tau }\end{array}$ & $\begin{array}{l}\text { standard } \\
\text { week }\end{array}$ & $\begin{array}{c}\text { Per Week } \\
\text { catches of } \\
\text { Z tau }\end{array}$ & $\begin{array}{l}\text { standard } \\
\text { week }\end{array}$ & $\begin{array}{c}\text { Per Week } \\
\text { catches of } \\
\mathrm{Z} \text { tau }\end{array}$ & $\begin{array}{c}\text { standard } \\
\text { week }\end{array}$ & $\begin{array}{c}\text { Per } \\
\text { Week } \\
\text { catches } \\
\text { of } Z \text { tau }\end{array}$ \\
\hline \multicolumn{2}{|c|}{ Year 2015} & \multicolumn{4}{|c|}{ Year 2016} & \multicolumn{2}{|c|}{ Year 2017} \\
\hline 27 & 40 & 1 & 11 & 27 & 38 & 1 & 12 \\
\hline 28 & 44 & 2 & 8 & 28 & 34 & 2 & 10 \\
\hline 29 & 36 & 3 & 12 & 29 & 29 & 3 & 12 \\
\hline 30 & 35 & 4 & 10 & 30 & 32 & 4 & 10 \\
\hline 31 & 32 & 5 & 18 & 31 & 29 & 5 & 20 \\
\hline 32 & 33 & 6 & 22 & 32 & 35 & 6 & 27 \\
\hline 33 & 41 & 7 & 30 & 33 & 43 & 7 & 26 \\
\hline 34 & 47 & 8 & 39 & 34 & 44 & 8 & 20 \\
\hline 35 & 63 & 9 & 37 & 35 & 48 & 9 & 27 \\
\hline 36 & 58 & 10 & 46 & 36 & 62 & 10 & 49 \\
\hline 37 & 53 & 11 & 42 & 37 & 62 & 11 & 56 \\
\hline 38 & 49 & 12 & 48 & 38 & 61 & 12 & 48 \\
\hline 39 & 57 & 13 & 73 & 39 & 44 & 13 & 40 \\
\hline 40 & 64 & 14 & 83 & 40 & 64 & 14 & 72 \\
\hline 41 & 55 & 15 & 72 & 41 & 65 & 15 & 63 \\
\hline 42 & 52 & 16 & 75 & 42 & 68 & 16 & 69 \\
\hline 43 & 44 & 17 & 63 & 43 & 50 & 17 & 56 \\
\hline 44 & 22 & 18 & 35 & 44 & 25 & 18 & 42 \\
\hline 45 & 16 & 19 & 30 & 45 & 17 & 19 & 35 \\
\hline 46 & 15 & 20 & 34 & 46 & 15 & 20 & 45 \\
\hline 47 & 17 & 21 & 42 & 47 & 17 & 21 & 34 \\
\hline 48 & 12 & 22 & 36 & 48 & 13 & 22 & 32 \\
\hline 49 & 13 & 23 & 43 & 49 & 10 & 23 & 34 \\
\hline 50 & 9 & 24 & 30 & 50 & 14 & 24 & 38 \\
\hline 51 & 12 & 25 & 30 & 51 & 9 & 25 & 33 \\
\hline 52 & 5 & 26 & 36 & 52 & 11 & 26 & 30 \\
\hline
\end{tabular}


Table.2 Correlation co-efficient between weather parameters and incidence of Zeugodacus tau

\begin{tabular}{|l|c|}
\hline Weather Parameters & $\begin{array}{c}\text { Correlation value with Mean weekly } \\
\text { trap catches }\end{array}$ \\
\hline Maximum Temperature & $0.685^{* *}$ \\
\hline Minimum Temperature & $0.637^{* *}$ \\
\hline Rainfall & $0.233^{*}$ \\
\hline Relative Humidity & $0.195^{*}$ \\
\hline (*= significant at $5 \%, * *=$ significant at both $1 \%$ and $5 \%$, NS $=$ Non-significant $)$ \\
\hline
\end{tabular}

Table.3 Multiple regression between weather parameters and incidence of Z. tau

\begin{tabular}{|c|c|c|c|}
\hline Weather Parameters & Regression model & $\begin{array}{l}\text { Standard } \\
\text { Error }\end{array}$ & P-value \\
\hline Maximum Temperature $\left(\mathrm{x}_{1}\right)$ & \multirow{4}{*}{$\begin{array}{l}Y=-31.63+2.75 x_{1}+1.39 \quad x_{2}-0.001 \quad x_{3}-0.619 \\
\quad x_{4}\end{array}$} & 1.012 & 0.008 \\
\hline Minimum Temperature $\left(\mathbf{x}_{2}\right)$ & & 0.654 & 0.036 \\
\hline Rainfall $\left(\mathbf{x}_{3}\right)$ & & 0.024 & 0.966 \\
\hline Relative Humidity $\left(x_{4}\right)$ & & 0.291 & 0.036 \\
\hline
\end{tabular}

Fig.1 Seasonal incidence of fruit fly (Per Week catches of Z tau)

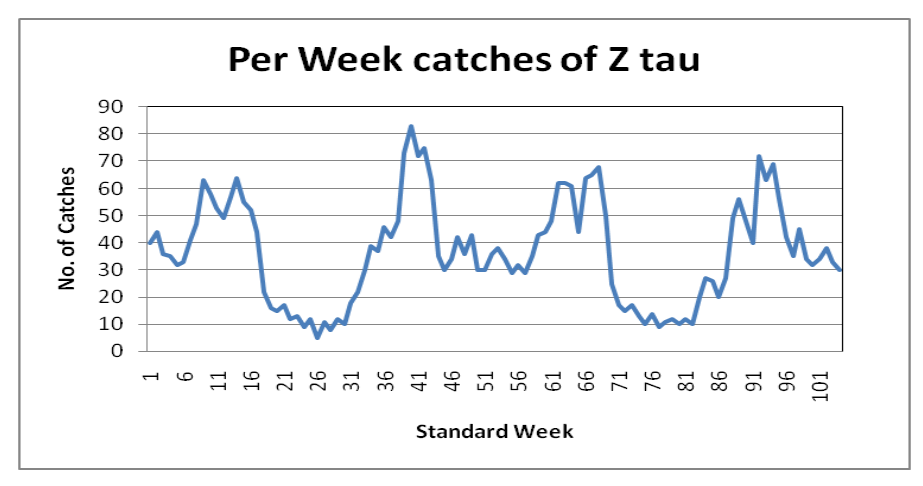

Effect of abiotic factors on fruit fly adult abundance

Studies to find out the relationship between trap catches of $Z$. tau and weather parameters such as maximum and minimum temperature, rainfall and relative humidity during the present work has revealed that there is significant positive correlation with maximum $(\mathrm{r}=0.685)$ and minimum $(\mathrm{r}=0.637)$ temperature at both $1 \%$ and $5 \%$ level of significance and also with rainfall $(\mathrm{r}=0.233)$ and relative humidity $(\mathrm{r}=0.195)$ at $5 \%$ level of significance (Table 2).
The multiple linear regression analysis between Z. tau and the weather parameters revealed that maximum temperature and minimum temperature have significant influence and rainfall and relative humidity have non-significant influence on seasonal incidence (dependent variable) of Z. tau population. All the weather factors together influenced the fruit fly trap catches to the extent of 49.8 percent. The multiple linear regression model fitted was $\mathrm{Y}=-31.63+2.75$ $\mathrm{x}_{1}+1.39 \quad \mathrm{x}_{2}-0.001 \quad \mathrm{x}_{3}-0.619 \quad \mathrm{x}_{4}$. Where, $\mathrm{x}_{1}=$ Maximum temperature, $\mathrm{x}_{2}=$ Minimum temperature, $\mathrm{x}_{3}=$ Rainfall, $\mathrm{x}_{4}=$ relative humidity (Table 3 ). 
The present finding is in conformity with Hasyim et al., (2008) who observed that fruit fly population correlated positively with all three abiotic factors (rainfall per day, number of rainy days, and average day temperature) studied. However, in contrary to the present findings Hossain et al., (2019) reported that incidence of $Z$. tau was inversely related to rainfall and temperature, with abundance peaks during the dry and cooler winter months. Information regarding seasonal incidence of $Z$. tau from India is meagre. Gupta and Verma (1992) studied the population fluctuations of $B$. cucurbitae and $B$. tau infesting cucurbitaceous crops and observed that fruit fly incidence was closely associated with weather factors and pest status changes rapidly owing to dynamic nature of the environment.

In the present study also close association of $Z$. tau incidence with weather factors has been recorded. Sawai et al., (2019) through their one year's study reported that Z. tau had significant positive correlation with maximum relative humidity which is in conformity with the present study. However, many workers have studied the seasonal incidence of another important and more commonly known fruit fly pest of Cucurbits i.e. melon fly ( $Z$ cucurbitae) (Raghuvanshi et al., 2012; Sunil et al., 2016; Abhilash et al., 2017; Sawai et al., 2019). Sawai et al., (2019) noticed population of adult flies of $Z$. cucurbitae throughout the period in cue lure traps, however, the peak activity was recorded from third week of September to the last week of October with a distinct peak in the last week of September. Sawai et al., (2019) studied the correlation of $Z$. cucurbitae population with weather parameters and found significantly positive correlation of the fly catch in the cue lure baited trap with average temperature and negative correlation with bright sunshine hours. Sunil et al., (2016) recorded peak of Fruit fly infestation on bitter gourd during last week of September (52\%) and in last week of February $(33 \%)$. Incidence of fruit fly in kharif recorded significant positive correlation with rainfall $(\mathrm{r}=0.71)$ and positively correlated with maximum temperature $(\mathrm{r}=0.35)$ and maximum $\mathrm{RH}(\mathrm{r}=$ 0.59 ) while during rabi, there was significant positive correlation with maximum temperature $(\mathrm{r}=0.76)$. Abhilash et al., (2017) found significant positive correlation of melon fruit fly incidence with maximum and minimum temperature but significant negative correlation with afternoon relative humidity and rainfall. According to Wazir et al., (2019) the population of Bactrocera cucurbitae was highly significant and positively correlated with mean relative morning humidity, relative evening humidity and rainfall but highly negatively correlated with maximum temperature.

In conclusion the evident from the present findings that the population of $Z$. tau is positively correlated with the environmental factors of which maximum temperature and minimum temperature have significant influence on $Z$. tau. In the climatic condition of Tripura this species of fruit fly is prevalent all through out the year with two peaks, one during last week of March- April and another one during September-October. So, this information generated from the present study may be utilized in planning and formulating management strategies for effective suppression of this important pest of cucurbitaceous crops in Tripura.

\section{Acknowledgement}

The authors are grateful to the Principal, College of Agriculture, Tripura for the liberal facilities provided for this study. The authors are also grateful to the ICAR, Lembucherra, Tripura for providing the meteorological data required for this study. 


\section{References}

Abhilash J., Naveen N.E., Patil S.U., Sharanabasappa and Mohankumar K.S. 2017. Monitoring of melon fruit fly (Bactrocera cucurbitae) Col. (Diptera: Tephritidae) in relation to weather parameters. Journal of Entomology and Zoology Studies. 5(5): 1930-1935.

Allwood A.J., Chinajariyawong A., Kritsaneepaiboon S., Drew R.A.I., Hamacek E.L., Hancock D.L., Hengsawad C., Jipanin J.C., Jirasurat M., Krong C.K., Leong C.T.S., Vijaysegaran S. 1999. Host plant records for fruit flies (Diptera: Tephritidae) in Southeast Asia. The Raffles Bulletin of Zoology (Supplement). 7: 1-92.

Boopathi T., Singh S.B., Manju T., Chowdhury S., Singh A.R., Dutta S.K. et al. 2017. First report of economic injury to tomato due to Zeugodacus tau (Diptera: Tephritidae): relative abundance and effects of cultivar and season on injury. Florida Entomologist. 100(1): 63-69.

Drew R.A.I. and Romig M.C. 2013. Tropical Fruit Flies (Tephritidae: Dacinae) of South-East Asia. CAB International, Wallingford. $653 \mathrm{pp}$.

Gupta D. and Verma A.K. 1992. Population fluctuations of the maggots of fruit flies Dacus cucurbitae Coquillett and D. tau (Walker) infesting cucurbitaceous crops. Advances of Plant Sciences. 5: 518-523.

Hasyim A., Muryati M., and Kogel W d. 2008. Population fluctuation of adult males of the fruit fly, Bactrocera tau Walker (Diptera: Tephritidae) in passion fruit orchards in relation to a biotic factors and sanitation. Indonesian Journal of Agricultural
Science. 9(1): 29-33.

Hossain M.A., Leblanc L., Momen M., Abdul Bari M., Khan S.A. 2019. Seasonal Abundance of Economically Important Fruit Flies (Diptera: Tephritidae: Dacinae) in Bangladesh, in Relation to Abiotic Factors and Host Plants. Proceedings of the Hawaiian Entomological Society. 51(2):25-37.

Kapoor V.C. 2005/06. Taxonomy and biology of economically important fruit flies of India. In: Biotaxonomy of Tephritoidea. Isr. Journal of Entomology. 35-36: 459- 475.

Li X., Yang H., Hu K. and Wang J. 2020. Temporal dynamics of Bactrocera (Zeugodacus) tau (Diptera: Tephritidae) adults in north Jiangxi, a subtropical area of China revealed by eight years of trapping with cuelure. Journal of Asia-Pacific Entomology. 23: 1-6.

Nair N., Thangjam B.C., Bhattacharjee T. and Debnath M.R. 2017. Species composition of Dacine fruit flies (Diptera: Tephritidae: Dacinae: Dacini) associated with Cucurbits in Tripura, a North Eastern state of India. Journal of Entomology and Zoology Studies. 5(3): 330-335.

Raghuvanshi A.K., Satpathy S. and Mishra D.S. 2012. Role of abiotic factors on seasonal abundance and infestation of fruit fly, Bactrocera cucurbitae (coq.) on bitter gourd. Journal of Plant Protection Research. 52(2): 264-267.

Sawai H.R., Godase S.K., Narangalkar A.L., Navik Omprakash. 2019. Population fluctuation of fruit flies in cucurbit ecosystem. Journal of Entomological Research. 43(2): $149-152$.

Singh S.K., Kumar D. and Ramamurthy V.V. 2010. Biology of Bactrocera (Zeugodacus) tau (Walker) (Diptera: Tephritidae). Entomological 
Research. 40: 259-263.

Sunil, Tippaiah, M. and Jayaram, C.S. 2016. Seasonal Incidence of Fruit Borers with Special Reference to Melon Fruit Fly, Bactrocera cucurbitae (Coquillet) on Bitter Gourd (Momordica charantia L.). Int. J. Pure App. Biosci. 4(3): 87-92.

Wazir Z.A., Singh A. K. and Ramana N.
2019. Seasonal incidence of fruit fly on Summer squash (Cucurbita pepo L.) and effect of weather parameters on population dynamics of fruit fly Bactrocera cucurbitae (Coquillett). Journal of Entomology and Zoology Studies. 7(5): 167-170.

\section{How to cite this article:}

Navendu Nair, Prasenjit Pal and Dilip Nath. 2020. Seasonal Incidence of Fruit Fly (Zeugodacus tau) in Cucurbit Ecosystem in Tripura. Int.J.Curr.Microbiol.App.Sci. 9(11): 971-977. doi: https://doi.org/10.20546/ijcmas.2020.911.115 